\title{
Anaemia management with subcutaneous epoetin delta in patients with chronic kidney disease (predialysis, haemodialysis, peritoneal dialysis): results of an open-label, I-year study
}

\author{
Ulrich Frei*1, Jonathan TC Kwan ${ }^{\dagger 2}$, Bruce S Spinowitz ${ }^{\dagger 3}$ and The Epoetin \\ Delta 3002 Study Group
}

Address: ${ }^{1}$ Department of Nephrology and Medical Intensive Care, Campus Virchow-Klinikum, Charité-Universitätsmedizin Berlin, Berlin, Germany, ${ }^{2}$ Medical Lead for Renal Services, SW Thames Renal \& Transplantation Unit, Epsom \& St Helier University Hospitals NHS Trust, St Helier Hospital, Carshalton, Surrey, UK and ${ }^{3}$ Weill Cornell Medical College, New York, NY, USA

Email: Ulrich Frei* - ulrich.frei@charite.de; Jonathan TC Kwan - Jonathan.Kwan@epsom-sthelier.nhs.uk; Bruce S Spinowitz - bss9001@nyp.org; The Epoetin Delta 3002 Study Group - lrich.frei@charite.de

* Corresponding author †Equal contributors

Published: 25 February 2009

BMC Nephrology 2009, 10:5 doi:10.1186/147|-2369-10-5
Received: 30 July 2008

Accepted: 25 February 2009

This article is available from: http://www.biomedcentral.com/I47I-2369//0/5

(c) 2009 Frei et al; licensee BioMed Central Ltd.

This is an Open Access article distributed under the terms of the Creative Commons Attribution License (http://creativecommons.org/licenses/by/2.0), which permits unrestricted use, distribution, and reproduction in any medium, provided the original work is properly cited.

\begin{abstract}
Background: Anaemia is common in patients with chronic kidney disease (CKD) and can be managed by therapy with erythropoiesis-stimulating agents (ESAs). Epoetin delta (DYNEPO ${ }^{\circledR}$, Shire plc) is the only epoetin produced in a human cell line. The aim of this study was to demonstrate the safety and efficacy of subcutaneously administered epoetin delta for the management of anaemia in CKD patients (predialysis, peritoneal dialysis or haemodialysis)

Methods: This was a I-year, multicentre, open-label study. Patients had previously received epoetin subcutaneously and were switched to epoetin delta at an identical dose to their previous therapy. Dose was titrated to maintain haemoglobin at $10.0-12.0 \mathrm{~g} / \mathrm{dL}$. The primary endpoint was mean haemoglobin over Weeks 12-24. Secondary analyses included long-term haemoglobin, haematocrit and dosing levels. Safety was assessed by monitoring adverse events, laboratory parameters and physical examinations.

Results: In total 478 patients received epoetin delta, forming the safety-evaluable population. Efficacy analyses were performed on data from $4 \mathrm{II}$ of these patients. Mean \pm SD haemoglobin over Weeks I2-24 was II.3 \pm I.I g/dL. Mean \pm SD weekly dose over Weeks I2-24 was $84.4 \pm 72.7$ $\mathrm{IU} / \mathrm{kg}$. Haemoglobin levels were maintained for the duration of the study. Epoetin delta was well tolerated, with adverse events occurring at rates expected for a CKD patient population; no patient developed anti-erythropoietin antibodies.
\end{abstract}

Conclusion: Subcutaneously administered epoetin delta is an effective and well-tolerated agent for the management of anaemia in CKD patients, irrespective of dialysis status.

Trial registration: http://www.controlled-trials.com ISRCTN68321818 


\section{Background}

Chronic kidney disease (CKD) is a prevalent and increasing health concern worldwide, and anaemia is a frequent complication of CKD $[1,2]$. The main cause of anaemia in patients with CKD is insufficient synthesis of erythropoietin by the damaged kidney. Since the 1980s, erythropoiesis-stimulating agents (ESAs) have been used to treat CKD-associated anaemia. Anaemia management with ESAs is a successful and well-tolerated therapy that has been demonstrated to improve quality of life and positively influence outcomes [3-6].

Until now ESAs have all been recombinant erythropoietins produced in Chinese hamster ovary $(\mathrm{CHO})$ cell lines, however a new epoetin, epoetin delta (DYNEPO ${ }^{\oplus}$, Shire plc), is the only one produced in a human cell line $[7,8]$. Epoetin delta has an identical amino acid structure to endogenous human erythropoietin, as is also the case for epoetin alfa and epoetin beta [7]. However differences in glycosylation profile between epoetin delta and the CHOcell-derived epoetins have been demonstrated, such as lower levels of certain non-human carbohydrate residues (N-glycolylneuraminic acid) in epoetin delta [8].

Phase II clinical trials with epoetin delta demonstrated that it is effective in increasing haemoglobin levels when administered intravenously (three times per week) to haemodialysis patients [9] and subcutaneously (twice per week) to CKD patients not on dialysis [10]. A 24-week, phase III trial in haemodialysis patients comparing epoetin delta and epoetin alfa, administered intravenously three times per week, demonstrated equivalent efficacy between the two agents [11]. An open-label extension to the study showed continued efficacy of epoetin delta in this haemodialysis population throughout the 52 weeks of study [12]. Efficacy of epoetin delta in a subgroup of predialysis patients has also been previously described [13]. Epoetin delta was well tolerated in all of these phase II and phase III studies. Additionally, phase I and II studies demonstrated that the half-life of subcutaneously administered epoetin delta is similar to the half-life of epoetin beta [14], an agent that can be administered once per week, and even once every 2 weeks in maintenance patients $[15,16]$.

Here, we report on an open-label, phase III study to assess the efficacy and safety of epoetin delta, administered subcutaneously once, twice or three times per week for the treatment of anaemia in haemodialysis, peritoneal dialysis and predialysis patients with CKD.

\section{Methods}

Patients

Patients with CKD (aged 18 years or older) and a medical history of anaemia (defined as haemoglobin $<11 \mathrm{~g} / \mathrm{dL}$ ) were eligible to enter the study. Predialysis patients had serum creatinine $>2 \mathrm{mg} / \mathrm{dL}\left(176.8 \mu \mathrm{mol} \mathrm{L}^{-1}\right)$ or creatinine clearance rates of $<45 \mathrm{~mL} / \mathrm{min}$ (by either 24-h urine collection or Cockcroft-Gault formula), equating to CKD stage 3 or 4 . All patients had haemoglobin levels in the range of 9.6-12.4 g/dL for the 2 weeks before entering the study. In the 30 days before entering the study haemodialysis patients were receiving an epoetin (epoetin alfa or beta) subcutaneously, two or three times per week, while peritoneal dialysis patients and those not on dialysis were receiving an epoetin subcutaneously at least once per week. During this 30-day period the dose of the epoetin had not changed by $>50 \%$ (either increase or decrease).

Patients had to have serum ferritin $\geq 90 \mathrm{ng} / \mathrm{mL}$ and transferrin saturation $\geq 18 \%$ at the prestudy measurement. Sufficient iron to maintain serum ferritin $\geq 100 \mathrm{ng} / \mathrm{mL}$ and transferrin saturation $\geq 20 \%$ was specifically required during the study. If iron status measurements fell short of these criteria then patients received intravenous iron supplementation of at least $1000 \mathrm{mg}$, over a maximum of 10 weeks. For haemodialysis patients, iron was administered within the first 90 minutes of the dialysis session. At study centres in France oral iron supplementation was attempted before use of the intravenous route for predialysis and peritoneal dialysis patients, and for haemodialysis patients intravenous iron therapy was initiated within the first few minutes of the dialysis session.

Exclusion criteria included uncontrolled hypertension, concomitant illness that could reduce life expectancy to $<$ 12 months, thrombocytopenia (platelet count $<75$ 000/ $\mathrm{mm}^{3}$ ), impaired hepatic function, previous treatment with epoetin delta, and pregnancy or breastfeeding at the prestudy screening. Also excluded were women of childbearing potential not using effective contraceptive methods.

The study was performed in accordance with the Declaration of Helsinki and was approved by local ethics committees at the individual study centres. All patients gave written informed consent before undergoing any study related procedures.

\section{Study Design}

This was a multicentre, open-label, uncontrolled study to assess the safety and efficacy of subcutaneously administered epoetin delta over 1 year. The study was carried out at sites in the USA and Europe between 1998 and 2000.

Epoetin delta was administered subcutaneously once, twice or three-times per week, at the same frequency as patients received before entering the study. The initial dose of epoetin delta was identical to the last dose of epoetin the patient received before entering the study. This 
dose was maintained for 2 weeks with subsequent titration to maintain haemoglobin at $10-12 \mathrm{~g} / \mathrm{dL}$, in keeping with the European Best Practice Guidelines in place at the time of the study [17]. Titration was as follows: dose was increased by $50 \%$ if haemoglobin dropped below $10 \mathrm{~g} / \mathrm{dL}$ or decreased by $25 \%$ if haemoglobin was above $12 \mathrm{~g} / \mathrm{dL}$. Dose was also altered if a patient's dry weight changed by more than $5 \mathrm{~kg}$. Dose adjustment based on haemoglobin level was only performed once in every 4-week period.

\section{Endpoints and analysis}

Haematological parameters were assessed weekly for the the first 12 weeks of the study and thereafter every 4 weeks. The primary efficacy endpoint was average haemoglobin over Weeks 12, 16, 20 and 24. Efficacy analyses were performed on data from a modified intent-to-treat (mITT) population consisting of all patients who had a valid haemoglobin measurement at baseline and at least one haemoglobin measurement during Weeks 12, 16, 20 or 24. An analysis of the primary endpoint was also carried out in the ITT population using last observation carried forward and first observation carried back techniques. In addition, an adjusted average haemoglobin was calculated with an ANCOVA model including parameters for dialysis type, pooled centre, and covariates of baseline haemoglobin and baseline epoetin dose.

Secondary analyses included: epoetin delta dose levels; descriptive statistics of haemoglobin and haematocrit levels; the proportion of patients' haemoglobin values over $10 \mathrm{~g} / \mathrm{dL}$ and the proportion of patients' haematocrit values over 30\% during Weeks 12-24; and haematological parameters and dosing over the 52 weeks of the study.

Safety assessments were conducted by recording and monitoring adverse events at each visit. Laboratory safety assessments were carried out every 4 weeks, and physical examinations and ECG at baseline, mid-study and at the end of the study (or early withdrawal). Anti-erythropoietin antibodies were screened for by validated ELISA (Quintiles Inc., Kansas City, MO) on samples collected at baseline and then every 4 weeks for the duration of the trial.

\section{Results \\ Patients}

Of 865 patients screened, 478 met the inclusion criteria and entered the study (Figure 1), forming the ITT population. All patients in the ITT population received at least one dose of epoetin delta and were included in the safetyevaluable population. The mITT population consisted of $411(86.0 \%)$ patients. This decrease from the ITT population is not surprising, given that criteria for inclusion in this group required completion of 12 weeks of treatment. The majority of haemodialysis patients received epoetin

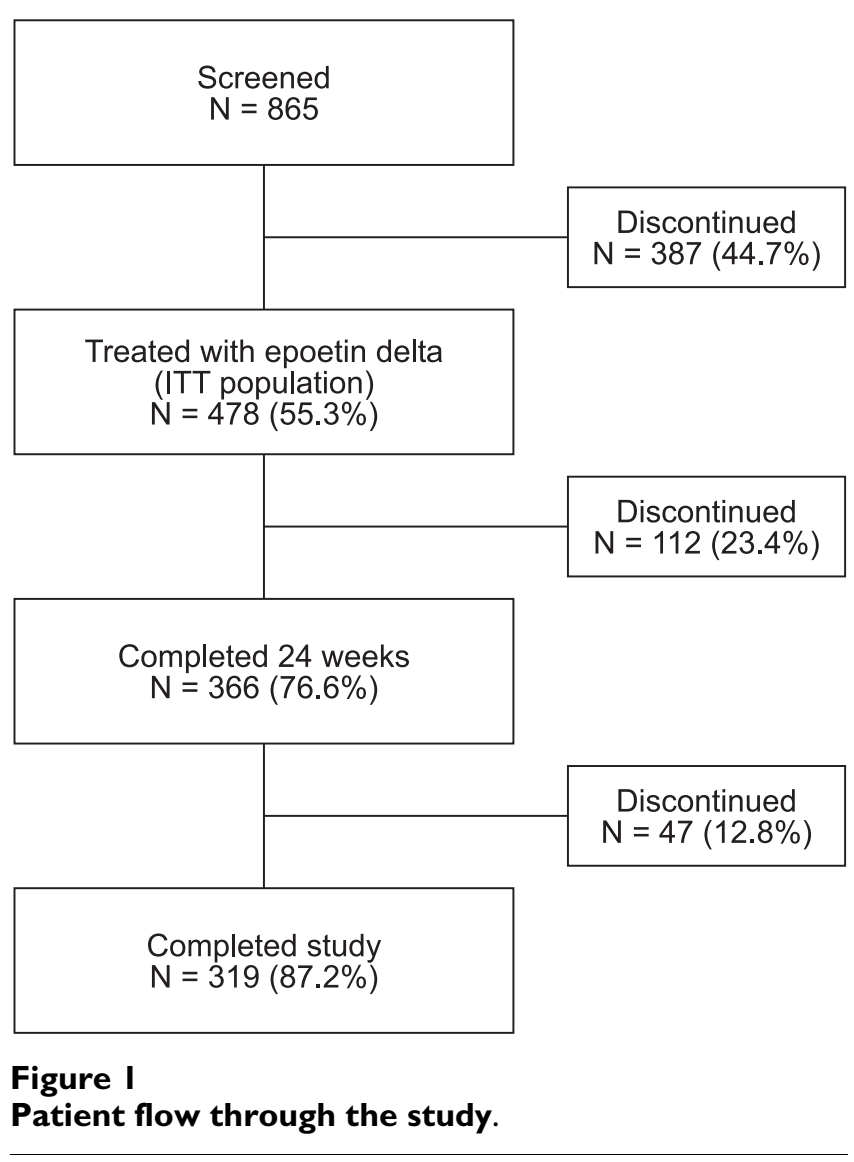

delta three-times or twice per week, while the majority of peritoneal dialysis and predialysis patients received epoetin delta once per week (Table 1). Baseline demographics for the mITT population are shown by both dialysis type and frequency of epoetin delta administration (Table 2).

The most common primary diagnoses for the causes of CKD were hypertensive nephrosclerosis (118/411; $28.7 \%$ ) and diabetic nephropathy $(97 / 411 ; 23.6 \%)$. Overall $34.5 \%$ (142/411) of patients had a medical history of either Type 1 or Type 2 diabetes.

Overall mean \pm SD haemoglobin at baseline was $11.1 \pm$ $0.9 \mathrm{~g} / \mathrm{dL}$ (mean haematocrit of $35.0 \pm 3.0 \%$ ) and haemoglobin levels were similar across all dialysis types and administration frequencies (Table 3).

Of those patients receiving study medication, 366/478 (76.6\%) completed 24 weeks of treatment and 319/478 (66.7\%) completed the study. The most common reasons for withdrawal in the first 24 weeks were: red blood cell transfusion $(27 / 112 ; 24 \%)$; patient did not wish to continue $(13 / 112 ; 11.6 \%)$ and death $(13 / 112 ; 11.6 \%)$. In addition 19 patients in Europe were withdrawn because of a sterility test failure on a batch of study drug. Subsequent 
Table I: Frequency of administration by dialysis type and total patients ( $\mathrm{mITT}$ population; $\mathrm{N}=4 \mathrm{II}$ )

\begin{tabular}{lcccc}
\hline & \multicolumn{3}{c}{ Number (\%) of patients } \\
\hline Frequency of administration & Predialysis $(\mathrm{n}=32)$ & Haemodialysis $(\mathrm{n}=288)$ & Peritoneal dialysis $(\mathrm{n}=9 \mathrm{I})$ & Total $(\mathrm{N}=4 \mathrm{II})$ \\
\hline $3 \times$ per week & 0 & $152(52.8)$ & $6(6.6)$ & $17(18.7)$ \\
\hline $2 \times$ per week & $2(6.3)$ & $131(45.5)$ & $68(74.7)$ & $150(38.4)$ \\
\hline $\mathrm{I}$ per week & $30(93.8)$ & $5(1.7)$ & $103(25.1)$ \\
\hline
\end{tabular}

investigation indicated that no contamination of drug substance was present and there was a high probability that external contamination of the cap was responsible for the test failure. Other reasons for discontinuation included: missed more than six doses $(n=8)$; kidney transplant $(\mathrm{n}=8)$; patient no longer met entry criteria ( $\mathrm{n}$ $=7)$; adverse event $(n=6)$; patient transferred to another facility $(n=3)$; patient not previously prescribed an epoetin according to protocol for dialysis type $(n=3)$; miscellaneous (chemotherapy, surgery, investigator decision [n $=3]$ ) and screening results not received in time $(n=2)$.
The most common reasons for withdrawal during Weeks 24-52 were death $(15 / 366 ; 4.1 \%)$, worsening adverse event $(9 / 366 ; 2.5 \%)$, patient did not wish to continue $(8 /$ $366 ; 2.2 \%)$, red blood cell transfusion $(4 / 366 ; 1.1 \%)$ and kidney transplant $(4 / 366 ; 1.1 \%)$.

\section{Efficacy assessments}

Overall mean \pm SD haemoglobin level for Weeks 12-24 was $11.3 \pm 1.1 \mathrm{~g} / \mathrm{dL}$, with mean haemoglobin levels maintained at 10-12 g/dL (within the target range) irrespective of dialysis type or administration frequency in the mITT

Table 2: Baseline demographics by frequency of administration, dialysis type and total patients ( $\mathrm{mITT}$ population; $\mathrm{N}=4 \mathrm{I} \mathrm{I}$ )

$$
\text { Number (\%) of patients (except as noted) }
$$

\begin{tabular}{|c|c|c|c|c|c|c|c|}
\hline & \multicolumn{3}{|c|}{ By frequency of administration } & \multicolumn{3}{|c|}{ By dialysis type } & \multirow[b]{2}{*}{ Total $(N=4 I I)$} \\
\hline & $\begin{array}{c}3 \times \text { weekly } \\
(\mathrm{n}=158)\end{array}$ & $\begin{array}{l}2 \times \text { weekly } \\
(n=150)\end{array}$ & $\begin{array}{l}\text { I } \times \text { weekly } \\
(n=103)\end{array}$ & $\begin{array}{l}\text { Predialysis } \\
(\mathrm{n}=32)\end{array}$ & $\begin{array}{l}\text { Haemo-dialysis } \\
\qquad(\mathrm{n}=288)\end{array}$ & $\begin{array}{c}\text { Peritoneal } \\
\text { dialysis }(n=91)\end{array}$ & \\
\hline \multicolumn{8}{|l|}{ Sex } \\
\hline Male & $101(63.9)$ & $82(54.7)$ & $50(48.5)$ & $13(40.6)$ & $175(60.8)$ & $45(49.5)$ & $233(56.7)$ \\
\hline Female & $57(36.1)$ & $68(45.3)$ & $53(5 \mathrm{I} .5)$ & $19(59.4)$ & $113(39.2)$ & $46(50.5)$ & $178(43.3)$ \\
\hline \multicolumn{8}{|l|}{ Age (Years) } \\
\hline $\begin{array}{l}\text { Mean } \\
( \pm \text { SD })\end{array}$ & $59.4(15.9)$ & $60.5(15.5)$ & $56.7(14.4)$ & $63.9(12.4)$ & $60.7(15.6)$ & $52.4(14.0)$ & $59.2(15.42)$ \\
\hline Median (range) & $\begin{array}{c}61 \\
(19-87)\end{array}$ & $\begin{array}{c}64 \\
(19-85)\end{array}$ & $\begin{array}{c}58 \\
(26-86)\end{array}$ & $\begin{array}{c}66 \\
(29-86)\end{array}$ & $\begin{array}{c}64 \\
(19-87)\end{array}$ & $\begin{array}{c}53 \\
(24-86)\end{array}$ & $\begin{array}{c}61 \\
(19-87)\end{array}$ \\
\hline \multicolumn{8}{|l|}{ Race } \\
\hline Caucasian & $110(69.6)$ & III (74.0) & $64(62.1)$ & $26(8 \mid .3)$ & $212(73.6)$ & $47(51.6)$ & $285(69.3)$ \\
\hline Black & $4 \mid(25.9)$ & $34(22.7)$ & $32(31.1)$ & $6(18.8)$ & $67(23.3)$ & $34(37.4)$ & $107(26.0)$ \\
\hline $\begin{array}{l}\text { Asian or } \\
\text { Oriental }\end{array}$ & $2(1.3)$ & $0(0.0)$ & $3(2.9)$ & $0(0.0)$ & $\mathrm{I}(0.3)$ & $4(4.4)$ & $5(1.2)$ \\
\hline Multiracial & $5(3.2)$ & $5(3.3)$ & $4(3.9)$ & $0(0.0)$ & $8(2.8)$ & $6(6.6)$ & $14(3.4)$ \\
\hline
\end{tabular}


Table 3: Haemoglobin levels by frequency of administration, dialysis type and total patients ( $\mathrm{mITT}$ population; $\mathrm{N}=4 \mathrm{I} \mathrm{I}$ )

\begin{tabular}{|c|c|c|}
\hline \multirow[b]{2}{*}{ Population by: } & \multicolumn{2}{|c|}{ Average haemoglobin (g/dL) (mean \pm SD) } \\
\hline & Baseline & Weeks I2-24 \\
\hline \multicolumn{3}{|c|}{ Frequency of administration } \\
\hline $3 \times$ per week $(n=158)$ & $11.0 \pm 0.9$ & $11.2 \pm 1.1$ \\
\hline $2 \times$ per week $(n=150)$ & $1 \mathrm{I} .1 \pm 0.8$ & $11.3 \pm 1.1$ \\
\hline $1 \times$ per week $(n=103)$ & $11.1 \pm 0.9$ & $11.5 \pm 1.2$ \\
\hline \multicolumn{3}{|l|}{ Dialysis type } \\
\hline Predialysis $(n=32)$ & $10.9 \pm 0.8$ & $11.3 \pm 1.2$ \\
\hline Haemodialysis $(n=288)$ & $11.1 \pm 0.8$ & $11.2 \pm 1.1$ \\
\hline Peritoneal dialysis $(n=91)$ & $11.2 \pm 0.9$ & $11.6 \pm 1.1$ \\
\hline Total $(N=4 I I)$ & $11.1 \pm 0.9$ & $11.3 \pm 1.1$ \\
\hline
\end{tabular}

population (Table 3 ). A similar overall value was obtained in the ITT population $(11.3 \pm 1.1 \mathrm{~g} / \mathrm{dL})$. The adjusted average level was $11.1 \pm 0.1 \mathrm{~g} / \mathrm{dL}$, indicating that dialysis type, baseline haemoglobin level and baseline dose did not greatly affect the results. Mean \pm SD haematocrit was 36.4 $\pm 3.7 \%$ over Weeks $12-24$, and mean haematocrit during this period was $>36 \%$ for all dialysis subgroups and administration frequencies (data not shown). Over Weeks $12-24,83.9 \%$ of haemoglobin measurements and $92.3 \%$ of haematocrit measurements were above the predefined lower limits of $10 \mathrm{~g} / \mathrm{dL}$ and 30\% respectively. Analyses of

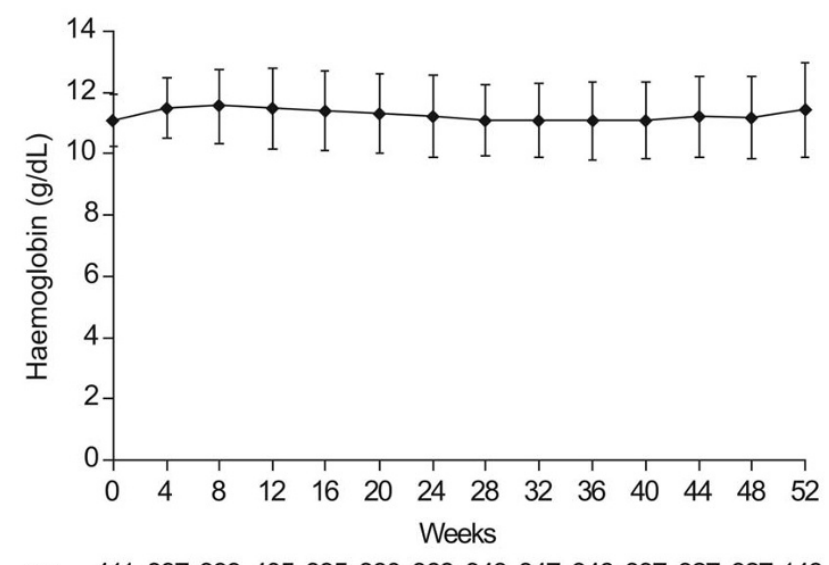

$n=411397399405395380368348347346337327327148$

\section{Figure 2}

Mean ( \pm SD) haemoglobin during the 52 weeks of study. haemoglobin for the 52-week duration of the study, showed levels were maintained at 10-12 g/dL (Figure 2).

The average weekly doses over Weeks $12-24$ and Weeks 37-52 are shown in Table 4, both by dialysis type and frequency of administration. Median dose was lowest for predialysis patients and highest for haemodialysis patients over Weeks 12-24. There were no marked differences in dose between Weeks 12-24 and Weeks 37-52. Mean and median weekly dose generally decreased with decreasing administration frequency, though the case mix in the three groups was different.

\section{Safety and tolerability}

Overall $86.8 \%(415 / 478)$ of patients experienced an adverse event during treatment, in line with the levels expected considering the baseline disease characteristics of this population. The most commonly reported adverse events were upper respiratory tract infection (19.5\%), infection (18.2\%), hypotension (16.7\%), headache (14.4\%) and muscle cramps (13.6\%). Overall, adverse events considered possibly related to treatment occurred in $12.3 \%$ (59/478) of patients (Table 5). The most commonly reported were hypertension and thrombosis. Serious adverse events (SAEs) were reported by $236 / 478$ (49.4\%) of patients, with rates similar across all dialysis types. SAEs considered possibly related to study medication occurred in $4.6 \%(22 / 478)$ of patients, and the majority of these were reported for patients undergoing haemodialysis $(17 / 22 ; 77.3 \%)$. Adverse events leading to withdrawal from the study occurred in $3.1 \%(15 / 478)$ of 
Table 4: Average weekly doses by frequency of administration, dialysis type and total patients (mITT population; $N=4 I I$ )

\begin{tabular}{|c|c|c|c|c|c|c|}
\hline \multirow{3}{*}{$\begin{array}{l}\text { Population by } \\
\text { Frequency of administration }\end{array}$} & \multicolumn{6}{|c|}{ Average weekly doses (IU/kg) } \\
\hline & \multicolumn{3}{|c|}{ Weeks I 2-24 } & \multicolumn{3}{|c|}{ Weeks 37-52 } \\
\hline & n (\%) & Mean \pm SD & Median (Range) & n (\%) & Mean \pm SD & Median (Range) \\
\hline $3 \times$ per week & $158(100.0)$ & $103.5 \pm 88.0$ & $77.9(13.3-804.0)$ & $126(79.8)$ & $114.4 \pm 130.7$ & $90.5(0.0-1293.6)$ \\
\hline $2 \times$ per week & $150(100.0)$ & $76.9 \pm 58.5$ & $62.2(11.5-417.5)$ & |3| (87.3) & $79.2 \pm 68.6$ & $62.01(2.5-436.5)$ \\
\hline I $\times$ per week & $103(100.0)$ & $65.9 \pm 57.8$ & $48.8(2.3-335.0)$ & $88(85.4)$ & $80.9 \pm 96.8$ & $47.5(0.0-622.6)$ \\
\hline \multicolumn{7}{|l|}{ Dialysis type } \\
\hline Predialysis & $32(100.0)$ & $87.7 \pm 73.5$ & $56.0(19.1-335.0)$ & $26(81.2)$ & $122.6 \pm 133.3$ & $73.2(14.9-622.6)$ \\
\hline Haemodialysis & $288(100.0)$ & $82.3 \pm 57.9$ & $66.5(2.3-396.0)$ & $242(84.0)$ & $90.5 \pm 102.6$ & $69.0(0.0-1293.6)$ \\
\hline Peritoneal dialysis & $91(100.0)$ & $89.8 \pm 107.3$ & $60.4(12.2-804.0)$ & $77(84.6)$ & $88.8 \pm 92.4$ & $61.9(4.4-436.5)$ \\
\hline Total & $4 I I(100.0)$ & $84.4 \pm 72.7$ & $64.8(2.3-804.0)$ & 345 (83.9) & $92.5 \pm 103.1$ & $66.0(0.0-1293.6)$ \\
\hline
\end{tabular}

patients, with six events considered possibly related to study medication (angio-oedema, hypertensive encephalopathy, hypertension, nausea, skin ulcers, pruritus).

Mean changes in laboratory analytes, vital signs and body weight from baseline to endpoint were minimal and there was no tendency for epoetin delta to induce ECG changes. During the 52 weeks of this trial no patient developed anti-erythropoietin antibodies or pure red cell aplasia.

Table 5: Adverse events (AE) considered possibly related to treatment and reported in $\geq 0.5 \%$ of patients (safety-evaluable population; $\mathbf{N}=\mathbf{4 7 8}$ )

\begin{tabular}{lc}
\hline AE & Number (\%) of patients \\
\hline Total & $59(12.3)$ \\
\hline Hypertension & $14(2.9)$ \\
\hline Thrombosis & $9(1.9)$ \\
\hline Anaemia & $5(1.0)$ \\
\hline Injection site pain & $5(1.0)$ \\
\hline Laboratory test abnormal* & $4(0.8)$ \\
\hline Erythrocyte abnormal & $3(0.6)$ \\
\hline Headache & $3(0.6)$ \\
\hline
\end{tabular}

* Laboratory test abnormal was the coded term for haemoglobin elevation $(n=2)$ and iron deficiency $(n=2)$

\section{Discussion}

Results from this open-label study show that subcutaneously administered epoetin delta, the only human-cellderived epoetin, was effective for the control of anaemia in this group of CKD patients (predialysis, peritoneal dialysis and haemodialysis) over 52 weeks. During the primary period of assessment (Weeks 12-24) haemoglobin levels were maintained within the target range of $10-12 \mathrm{~g} /$ $\mathrm{dL}$, in line with current recommendations [6]. Over $80 \%$ of haemoglobin and $90 \%$ of haematocrit measurements were above the predefined lower limits of $10 \mathrm{~g} / \mathrm{dL}$ and $30 \%$ respectively. A switch from prestudy therapy with subcutaneous epoetin alfa to subcutaneous epoetin delta was associated with continued control of haemoglobin levels for up to 1 year, across all dialysis types and administration frequencies of once, twice and three times per week. Epoetin delta was well tolerated for the duration of the study and no patient developed anti-erythropoietin antibodies or pure red cell aplasia.

The data demonstrate that epoetin delta is an acceptable alternative to other epoetins. It would appear that patients can be transitioned from other epoetins to epoetin delta at the same dose with no loss of control of anaemia. As noted previously, epoetin delta differs from other ESAs in that it is produced in a human cell line. It is not known whether this leads to any clinical advantages, but in theory it is possible that a different glycosylation pattern may have an impact on the pleiotropic effects of the agent. This requires further investigation. 
Our study has some limitations. The study was not blinded and did not include a control group and therefore results could possibly be due to factors other than treatment with epoetin delta. As entry criteria resulted in a study population that was previously responsive to epoetin treatment, our data provide no information on whether some patients may respond better to epoetin delta. It should also be noted that this study was completed before recent evidence regarding the potential harmful effects of fully correcting haemoglobin levels. From our data, we can not draw any conclusion as to whether epoetin delta was associated with any risk or benefit when associated with relatively high haemoglobin levels.

Further studies are underway to investigate potential benefits arising from the human-cell production of epoetin delta.

\section{Conclusion}

In this 52-week trial subcutaneously administered epoetin delta was shown to be an effective agent for the management of anaemia in patients with CKD. Predialysis patients and patients requiring peritoneal dialysis or haemodialysis were all able to maintain haemoglobin levels within the specified range, without marked changes in dosing regimen. Epoetin delta was well tolerated for treatment of up to 1 year and there was no evidence that it was capable of eliciting an immune response.

\section{Competing interests}

This study was sponsored by Hoechst Marion Roussel. The article processing charge will be financed by Shire plc. U Frei has received honoraria from Shire for consultancy and presentations. JTC Kwan and BS Spinowitz declare that they have no competing interests.

\section{Authors' contributions}

All authors enrolled patients in the study, contributed substantially to the development of the manuscript, and have read and approved the final paper.

\section{Acknowledgements}

The Epoetin Delta 3002 Study Group consisted of the following investigators:

USA: Paul Schneider, Todd Gehr, Kenneth Boren, Marcos Rothstin, Jay Wish, Barry Wood, Edward Ross, John Burkhart, Keith Keener, Brenda Smith, Jill Lindberg, Gary Matzke, James Strom, Duane Wombolt, Vito Campese, Kevin Martin, Bruce Spinowitz, Shashi Kant, S. Noor Rahman, Shetty Anupkumar, Suhail Ahmad, Jhoong Cheigh, Edward Kowalski, Jonathan Winston, Thomas Marbury, Mark Kipnes, Moses Spira, Thomas Cavalieri, Kenneth Kleinman.

France: Tilman Drüeke, Michel Aparicio, Francois Berthoux, Claude Buisson, Frederic Calaud, Patrice Deteix, Francis Ducret, Dominique Durand, Jean-Paul Fillastre, Patrick Francais, Olivier Kourilsky, Francois Kuentz,
Francoise Mignon, Delphine Morel, Michel Labeeuw, Pierre Simon, Philippe Vanhille, Michel Foret, Albert Fournier, Pablo Urena Torres, Jaques Cledes.

Germany: Ulrich Frei, Udo Bahner, Helmut Walter Geiger, Peter Piazolo, Christian Piper, Arnold Rockel, Roland Schafer, Gerd Offerman, Gunther Stein, Volker Weizman, Joachim Girndt, Harald Lange, Heinrich Kutemeyer, Helke Stier, Hjalmar Bernulf Steinhauer, Domonik Alscher, Rainer Nowack.

UK: Jonathan TC Kwan, Andrew Davenport, John David Williams.

Editorial assistance to the authors was provided by Oxford PharmaGenesis with the support of Shire plc.

DYNEPO ${ }^{\circledR}$ is a registered trademark of Hoechst $\mathrm{GmbH}$.

\section{References}

I. Hsu CY, McCulloch CE, Curhan GC: Epidemiology of anemia associated with chronic renal insufficiency among adults in the United States: results from the Third National Health and Nutrition Examination Survey. J Am Soc Nephrol 2002, I3:504-5 I0.

2. McClellan W, Aronoff SL, Bolton WK, Hood S, Lorber DL, Tang KL, Tse TF, Wasserman B, Leiserowitz M: The prevalence of anemia in patients with chronic kidney disease. Curr Med Res Opin 2004, 20:1501-1510.

3. Besarab A, Bolton WK, Browne JK, Egrie JC, Nissenson AR, Okamoto DM, Schwab SJ, Goodkin DA: The effects of normal as compared with low hematocrit values in patients with cardiac disease who are receiving hemodialysis and epoetin. $N$ Engl J Med 1998, 339:584-590.

4. Association between recombinant human erythropoietin and quality of life and exercise capacity of patients receiving haemodialysis. Canadian Erythropoietin Study Group. BMJ 1990, 300:573-578.

5. Revicki DA, Brown RE, Feeny DH, Henry D, Teehan BP, Rudnick MR, Benz RL: Health-related quality of life associated with recombinant human erythropoietin therapy for predialysis chronic renal disease patients. Am J Kidney Dis 1995, 25:548-554.

6. Locatelli F, Aljama P, Barany P, Canaud B, Carrera F, Eckardt KU, Horl WH, Macdougal IC, Macleod A, Wiecek A, et al.: Revised European best practice guidelines for the management of anaemia in patients with chronic renal failure. Nephrol Dial Transplant 2004, I 9(Suppl 2):ii I-47.

7. Deicher R, Horl WH: Differentiating factors between erythropoiesis-stimulating agents: a guide to selection for anaemia of chronic kidney disease. Drugs 2004, 64:499-509.

8. Shahrokh Z, Flatman S, Davies M, Baycroft A, Heartlein M: Erythropoietin produced by a human cell line has only trace levels of potentially immunogenic $\mathbf{N}$-glycolylneuraminic acid residues. haematologica/the hematology journal 2006, 9 I (SuppI I):208.

9. Spinowitz BS, Pratt RD: Epoetin delta is effective for the management of anaemia associated with chronic kidney disease. Curr Med Res Opin 2006, 22:2507-25I 3.

10. Pratt RD: Epoetin delta for the treatment of anemia in patients with CKD not requiring haemodialysis. Poster presented at the American Society of Nephrology Renal Week 2006.

II. Martin KJ: Epoetin delta in the management of renal anaemia: results of a 6-month study. Nephrol Dial Transplant 2007, 22:3052-3054.

12. Martin KJ: The first human cell line-derived erythropoietin, epoetin-delta (Dynepo), in the management of anemia in patients with chronic kidney disease. Clin Nephrol 2007, 68:26-3I.

13. Kwan JT, Pratt RD: Epoetin delta, erythropoietin produced in a human cell line, in the management of anaemia in predialysis chronic kidney disease patients. Curr Med Res Opin 2007, 23:307-3II.

14. Smith WB, Dowell JA, Pratt RD: Pharmacokinetics and pharmacodynamics of epoetin delta in two studies in healthy volunteers and two studies in patients with chronic kidney disease. Clin Ther 2007, 29:1368-1380. 
15. Weiss LG, Clyne N, Divino Fihlho J, Frisenette-Fich C, Kurkus J, Svensson B: The efficacy of once weekly compared with two or three times weekly subcutaneous epoetin beta: results from a randomized controlled multicentre trial. Swedish Study Group. Nephrol Dial Transplant 2000, I5:2014-2019.

16. Locatelli F, Baldamus CA, Villa G, Ganea A, Martin de Francisco AL: Once-weekly compared with three-times-weekly subcutaneous epoetin beta: results from a randomized, multicenter, therapeutic-equivalence study. Am J Kidney Dis 2002, 40:119-125.

17. European best practice guidelines for the management of anaemia in patients with chronic renal failure. Working Party for European Best Practice Guidelines for the Management of Anaemia in Patients with Chronic Renal Failure. Nephrol Dial Transplant 1999, I4(Suppl 5): I-50.

\section{Pre-publication history}

The pre-publication history for this paper can be accessed here:

http://www.biomedcentral.com/1471-2369/10/5/prepub

Publish with Bio Med Central and every scientist can read your work free of charge

"BioMed Central will be the most significant development for disseminating the results of biomedical research in our lifetime."

Sir Paul Nurse, Cancer Research UK

Your research papers will be:

- available free of charge to the entire biomedical community

- peer reviewed and published immediately upon acceptance

- cited in PubMed and archived on PubMed Central

- yours - you keep the copyright

Submit your manuscript here:

http://www.biomedcentral.com/info/publishing_adv.asp 